\title{
The Effects of Different Utilization Conditions on Species Richness Changes in Saral Rangelands, Kurdistan Province
}

\author{
Zare chahouki, Mohammad Ali \\ Assistant Professor, Department of Rehabilitation of Arid and Mountainous Regions \\ Faculty of Natural Resources, University of Tehran, Karaj, Iran
}

Bahram Gholinezhad

Phd. Student, Range management, University of Tehran

Asghar Farajollahi

Member of Young Researchers Club of Kurdistan

Jamal Imani (corresponding author)

M.Sc. student, Range management, University of Tehran, Karaj, Iran

Tel:98-918-979-5481Ｅ-mail: imany22@gmail.com

\begin{abstract}
Species richness, as a term that have implicated a number of species and specimens number of every species in a community, is one of the most important evaluation indices to quantity plants in rangeland ecosystems. This case study tries to evaluate the effect of different utilization levels on species richness in Saral. Therefore three areas (Reference, Key and Critical region) were determined for this evaluation. Then species richness data were collected by Whittaker plot in ten replications for any region and these data were analyzed by factorial experiment. Finally treatment mean (plot size and three declared area) were compared by Duncan's multiple range test. Results show that there are significant differences between treatments mean plot size and reference, key and critical regions in $\mathrm{P}<0.01$ but interaction effects (area $\times$ plot size) don't have a significant difference.
\end{abstract}

Keywords: Species Richness, Reference Area, Key Area, Critical Area, Saral Region, Kurdistan Province

\section{Introduction}

Rangelands possess attributes that give them potential for biodiversity. Since they have not been put to the plow, rangelands are attributed value as a natural system. Further, rangelands cover vast areas, often contiguously, and thereby possess the scale necessary for biodiversity of communities, ecosystems, and landscapes (West, 1993). Environmental factors affect rangeland plant diversity. The most ecologically important environmental factors affecting rangeland plant diversity are light, temperature, and water (precipitation). These factors have a permanent effect but the changes of management practices have a different effect. Before studies showed that species richness does not change under moderate grazing, and it can be improved rather than full protection condition, due to positive effect and stimulate of plants growth (Naveh and Whittaker, 1979). In a Study in Golestan National Park, it was found that species diversity under heavy utilization is decreased but in moderate and light grazing, it does not change (Ghlichnia, 2003). Maguran (1998) offers using medium utilization and avoiding of light and heavy utilization to achieve an acceptable profit, no damage to vegetation and soil, preserve species diversity and richness in pasture. Species richness is one of the most important indices to evaluate vegetation quantitative and qualitative changes to show ascending or descending trend (Mesdaghi, 2000). The effect of different utilization level on the species richness and diversity is different so that the heavy utilization decreases species richness (Cochran 1977). In a pasture ecosystem, stability is affected by utilization patterns of plants as vegetation cover changes can extremely decrease plant diversity and cause soil erosion. The protection of plant species richness not mean non-utilization, it refers to management of plants utilization time (Peet, 1967). Plants diversity in a pasture field is demonstrator of existence suitable condition for plant growth and reasonable utilization. Sharifi (1996) was compared the species diversity and plant forms under different utilization levels in 
different places of the natural habitats and showed that species richness and diversity increases in medium level of utilization while they decreases in light and non-utilization levels. Usher (1986) found that Species diversity and richness extremely changed by topography characteristics (aspect and height) and species richness increased by height increasing to certain point, express the climate has improved. Saral area is one of the most important rangeland in Iran and this area should be protected with special attention. The aim of this study is assess the effects of different utilization levels on the change of species richness in Saral herbaceous habitats, Kurdistan province.

\section{Materials and Methods}

The study area was bounded by $46^{\circ}-25^{\prime}$ to $46^{\circ}-50^{\prime} \mathrm{E}, 35^{\circ}-35^{\prime} \mathrm{N}$ to $35^{\circ}-55^{\prime} \mathrm{N}$. The total area of the region is 310105 ha. Medium height in region is $2250 \mathrm{~m}$ that use as a bungalow rangeland and its species are from Umbelliferae, Poaceae and Fabaceae family. The means of precipitation is $480 \mathrm{~mm} / \mathrm{year}$ that maximum and minimum of precipitation occur in February and July respectively. The mean of annual temperature is $13^{\circ} \mathrm{C}$. All plants in this region are in families of Fabaceae, Poaceae, Brassicaceae, Umbellifereae, Chenopodiaceae, Polygonaceae, Caryophyllaceae, Ranunculaceae, Papaveraceae, Euphorbiaceae, Geraniaceae, Rosaceae, Lamiaceae , Convolvulaceae, Boraginaceae , Campanulaceae , Asteraceae, Liliaceae , Iridaceae. For implementation this studies, initially were determined study area on 1:50000 map scale. Then experiment was conducted on three rangeland condition sites including: reference, key and critical regions (Moghadam 2002). The Reference region area was 10 ha that was between 2100 to $2450 \mathrm{~m}$ height of sea level. The Key region was between 1650 to $1690 \mathrm{~m}$ height of sea level with 5 ha area that non-observe the problem of soil degradation and soil erosion but exist invasive plant such as Achillea millefolium, Poa bulbosa, Hordeum morinum that represent the disturbing of ecological balance. Critical region determined in near of rural that was under heavy utilization and intensity grazing. In critical region observed poisons, spiny and invasive plants such as Carthamus sp, Echinops sp, Gundelia tourneforti, Poa bulbosa, Euphorbia sp.The height of sea level in this region is 1400 to $1500 \mathrm{~m}$. All mentioned regions were sampled using Whittaker plot from random-systematic method. Sampling site (reference, key and critical regions) selected using systematic method. The first plot and other plots set of random and systematic method respectively with ten replications. In all of Whittaker plots recorded total information about species diversity and richness in different utilization levels including: plant scientific name, species number, plants classification and plant growth forms. In the next step, the experiment was performed based on Randomized complete block design (RCBD). For this purpose, studied regions (reference, key and critical) and plot sizes $\left(0.1,1,10,100\right.$ and $\left.1000 \mathrm{~m}^{2}\right)$ were selected as first and second factors respectively. Experimental data was analyzed by MSTAT-C program (MSTAT-C, 1990). The differences between the means were compared using Duncan's multiple tests.

\section{Results}

The numbers of counted species in different plot sizes are showed in Tables 1,2 and 3. Table 4 and 5 shows variance analysis and comparison of means related to the number of species under effect regions and plot size (Duncan test). In key region, the major of plant belong to class I and II and in few regions that showed plants of class III, it because of grazing intensity. This trend is according to increasing plot size. In reference area with majority of plants in class I, that increasing plot size, increase to frequency percent of them and cause to decrease plants of class II in comparison to class I. in this region existed plants of class III but they were very low percent. In critical region, major of plants were poisonous, spiny and invasive that belong to class III, these plants are Echinops sp, Carthamus sp, Poa bulbosa. In critical region did not show plants of class I and plants of class II were very low number. The results show (table 4 ) the number of species in different utilization levels that set of in reference, key and critical regions were significant in $1 \%$ level. The effect of plot size on number species that obtained from mean differences represents species richness with plot size in $1 \%$ level but interaction effect (area $\times$ plot size) was not significant in mentioned probability level. Results of factorial experiment (table1) show that species number under different utilization level in reference, key and critical regions have a significant difference in $\mathrm{P}<0.01$. the Assessment of Plot size effect on species number can be concluded from different means treatment can be shows increasing species number (species richness) with increasing in plot size in $\mathrm{p}<0.01$. Interaction effect of (area $\times$ plot size) doesn't show a significant difference.

\section{Discussion and Conclusion}

Results show a significant difference of plant richness in reference and key regions $(\mathrm{P}<0.05)$ but there are no significant difference for species richness in $(\mathrm{P}<0.01)$. It can be concluded that plant remove, even in low extent, effects on plant richness in a given area. That species richness don't show a significant difference in key and reference area $(\mathrm{P}<0.01)$, can be interpret as grazing reduce species richness but it is not very noticeable and the 
key region condition is relatively similar to reference one. In the other word, light and medium utilization of a specific plant type have relatively similar effects on species richness. Therefore medium grazing preserves species richness properly. However data collected from critical compare to these from key and reference regions show a noticeable difference in mean values (fig 5) i.e. heavy grazing in critical area extremely reduce species richness and threat rangeland ecosystem seriously. Medium utilization not only preserves rangeland ecosystem components and species richness effectively but also conserves plant forms. In reference region, plant forms frequently composed of herbaceous forbs and graminus in relation to soil potential and ecological condition. These founding, confirm Mesdaghi study results, show that medium utilization not only don't decrease species richness but also develop uniform distribution of richness and diversity. Therefore, medium utilization completely develops plant distribution even better than enclosure condition. Heavy utilization in critical region reduces species richness and species diversity and it is extremely related to habitat condition and utilization rate. It is possible that species diversity initially increased and then extremely decreased by increasing habitat limitations as the rangeland area covered by invasive plants.

Factorial analysis on species number in different area and plot size show that there is a significant difference between reference, key and critical regions $(p<0.01)$ and species number significantly increased by plot size increase $(\mathrm{p}<0.01)$. Interaction effect (area $\times$ plot size) was not significant in this probability level. These founding confirm the significant effects of different utilization level on species richness (species number).

In these decades, some experts seek to get enclosure conditions and plant condition in reference region (Mesdaghi, 1995) but it is too hard to get climax condition in dry and semi arid regions, as Iran. In the other hand, this study, as some valuable studying, show that medium utilization preserve species richness in key region relatively similar to that's of reference region. Species richness will be even increases by low utilization rather than enclosure condition but species richness and diversity extremely decreased in critical region (confirm the results of Naveh and Whittaker (1979), West (1993), Sharifi (1996), Mesdaghi (2000)). Therefore, utilization management based on key region can be the best choice of rangeland utilization.

\section{References}

Bernardo, D. J., Engle, D. M., Lochmiller, R. L., \& McCollum, F. T. (1992). Optimal vegetation management under multiple use objectives in Goss timbers. Journal of Range Management, 45, 452-469.

Chammani, A. (1998). Assessment of species richness and diversity in Almeh and Mirza Bailo plain, Golestan National Park, M.Sc. thesis in rangeland management, University of Agriculture and Natural Resource Science of Gorgan. (In Persian).

Cingolani, A.M., Noy-Meir, I., \& Diaz, S. (2005). Grazing effects on rangeland diversity. A Synthesis of Contemporary Models, Ecological Applications, 15(2005), pp. 757-773.

Cochran, W. G. (1977). Sampling techniques. Third Edition. John Wiley and Sons, New York, USA, 428pp.

Freese, F. (1967). Elementary statistical methods for foresters, Agriculture handbook 317. USDA, 87pp.

Ghahreman, A. (1994). Cormophytes of Iran (Plant systematic). V.2., publication of center of University. Pp: 100- 800. (In Persian).

Ghahreman, A. (2002). Colorful flor of Iran, V.19, publication of research institute of forestry and rangeland. (In Persian).

Ghasriani, f. (1999). Identification of ecological regions of Iran, plant covers of Kurdistan province, Research institute of forestry and rangelands, no.227. (In Persian).

Ghlichnia, H. (2003). Comparing species diversity and frequency of forest flora in Mazandaran. Journal of Pajouhesh \& Sazandegi, 16(1), 37-41. (In Persian).

Grassle, J.F., Patil, G.P., Smith, W.K., \& Taillie, C. International Co-operative Publishing House. pp. 219-239.

Kimberly G. A., \& Hik, D. S. (2003). What determines disturbance-productivity-diversity relationships? The effect of scale, species and environment on richness patterns in an Australian woodland Oikos, 102 (1), 173-185.

Kitts, A.W. (1992). Economic value of some external costs for grasshopper control. M.S. thesis. Ft. Collins, CO: Colorado State University, Department of Agricultural and Resource Economics. 91p.

Loomis, J., Donnelly, D., \& Sorg-Swanson, C. (1989). Comparing the economic value of forage on public lands for wildlife and livestock, Journal of Range Management, 42, 134-138.

Maguran, A. E. (1988). Ecological diversity and its measurement, Princeton Univ, Press, Princeton, N.Y, 179 p. 
Mesdaghi, M. (1995). Range and range management in Iran, Emam reza University, V.2. Pp: 60-110. (In Persian).

Mesdaghi, M. (2000). Assessment of species richness and plant forms in three utilization levels of rangeland, J. of agriculture and natural resource science. (In Persian).

Moghadam, M. (2005). Range and range management, University of Tehran, 150-180. (In Persian).

Naveh, Z., \& Whittaker, R.H. (1979). Measurements and relationships of plant species diversity in Mediterranean shrub lands and woodlands. Ecological diversity in theory and practice. Statistical ecology theories Vol. 6. Edited by J.F.

Pabot, H. (1967). Pasture development and improvement through botanical and ecological studies, F.A.O.NO2311.

Peet, R.K. (1967). The measurement of species diversity, Annual Review of Ecology and Systematic, 5, 258-307.

Sadat Noori, S.A. (2005). Applied statistics and experimental design for agriculture science, volume 2 , University of Tehran. (In Persian).

Sadeghnezhad, M.R. (1997). Comparing diversity indices effectiveness in ecological of Robatic Gharebill, M.Sc. thesis in rangeland management, University of agriculture and natural resource science of Gorgan. (In Persian).

Sharifi, n. (1996). Species diversity and plant forms in natural habitats of Ardabil province, M.Sc. thesis in rangeland management, University of agriculture and natural resource science of Gorgan. (In Persian).

Standiford, R.B., \& Howitt, R.E. (1993). Multiple use management of California's hardwood rangelands, Journal of Range Management, 46, 176-182.

Tilman, D., \& Dowing, J.A. (1994). Biodiversity and stability in grasslands, Nature, 197 (6461), 363-365.

Usher, M.B. (1986). Wildlife conservation evaluation: attributes, Criteria and Values; in Wildlife Conservation Evaluation (ed.) Michael B Usher (London: Chapman and Hall) pp 3-44.

West, N. E. (1993). Biodiversity of rangelands, Journal of Range Management, 46, 2-13.

West, N.E. (1993). Biodiversity of Rangelands, Journal of Range Management, 46, 2-13.

Whittaker, N.E. (1965). Dominance and diversity in land plant communities. Science 149, 250-67.

Table 1. Number of counted species in key area with different plot size

\begin{tabular}{|c|c|c|c|c|c|}
\hline 1000 & 100 & 10 & 1 & 0.1 & $\begin{array}{r}\text { Plot size }\left(\mathrm{m}^{2}\right) \\
\text { replicate }\end{array}$ \\
\hline 17 & 12 & 8 & 5 & 2 & 1 \\
\hline 15 & 13 & 10 & 4 & 1 & 2 \\
\hline 18 & 15 & 9 & 3 & 0 & 3 \\
\hline 20 & 13 & 8 & 2 & 2 & 4 \\
\hline 17 & 11 & 6 & 3 & 1 & 5 \\
\hline 16 & 9 & 5 & 2 & 2 & 6 \\
\hline 14 & 7 & 4 & 3 & 1 & 7 \\
\hline 18 & 8 & 5 & 4 & 1 & 9 \\
\hline 17 & 10 & 6 & 3 & 0 & 10 \\
\hline 16 & 9 & 5 & 2 & 1 & \\
\hline
\end{tabular}


Table 2. Number of counted species in reference area with different plot size

\begin{tabular}{|c|c|c|c|c|c|}
\hline 1000 & 100 & 10 & 1 & 0.1 & Replicate \\
\hline 21 & 11 & 10 & 4 & 3 & 1 \\
\hline 16 & 10 & 9 & 3 & 2 & 2 \\
\hline 17 & 12 & 8 & 4 & 1 & 3 \\
\hline 18 & 14 & 10 & 6 & 3 & 4 \\
\hline 14 & 12 & 7 & 4 & 2 & 5 \\
\hline 18 & 10 & 8 & 3 & 3 & 6 \\
\hline 16 & 8 & 5 & 4 & 2 & 7 \\
\hline 21 & 7 & 6 & 5 & 2 & 8 \\
\hline 20 & 11 & 5 & 4 & 1 & 9 \\
\hline 18 & 10 & 6 & 3 & 1 & 10 \\
\hline
\end{tabular}

Table 3. Number of counted species in critical area with different plot size

\begin{tabular}{|c|c|c|c|c|c|}
\hline 1000 & 100 & 10 & 1 & 0.1 & (Plot size $\left(\mathrm{m}^{2}\right)$ \\
\hline 10 & 5 & 3 & 1 & 0 & 1 \\
\hline 7 & 5 & 4 & 1 & 1 & 2 \\
\hline 7 & 4 & 4 & 2 & 1 & 3 \\
\hline 9 & 5 & 3 & 2 & 0 & 4 \\
\hline 10 & 6 & 4 & 1 & 1 & 5 \\
\hline 6 & 4 & 3 & 2 & 0 & 6 \\
\hline 7 & 5 & 3 & 3 & 1 & 7 \\
\hline 5 & 5 & 4 & 2 & 0 & 8 \\
\hline 7 & 6 & 3 & 1 & 1 & 9 \\
\hline 9 & 5 & 4 & 2 & 0 & 10 \\
\hline
\end{tabular}

Table 4. Variance effect analysis of number species under effect regions and plot sizes by factorial experiment

\begin{tabular}{|c|c|c|c|c|}
\hline F & Mean Square & Sum of square & $\begin{array}{c}\text { Degrees of } \\
\text { freedom }\end{array}$ & Source of Changes \\
\hline $14.42^{* *}$ & 269.71 & 3775.92 & 14 & treatment \\
\hline $16.16^{* *}$ & 302.09 & 604.19 & 2 & region \\
\hline $38.60^{* *}$ & 721.88 & 2887.53 & 4 & Plot size \\
\hline $1.89^{\text {ns }}$ & 35.53 & 284.20 & 8 & (area $\times$ plot size) \\
\hline & 18.69 & 2262.61 & 121 & Test error \\
\cline { 2 - 5 } & & & 149 & total \\
\hline
\end{tabular}

** and Significant level, refer to $\% 0.1$ and ns no significant, respectively 
Table 5. comparing the means of species number in different areas and plot sizes

\begin{tabular}{|c|c|c|c|c|c|c|c|}
\hline \multicolumn{2}{|c|}{ Mean } & \multirow[t]{2}{*}{1000} & \multirow[t]{2}{*}{100} & \multirow[t]{2}{*}{10} & \multirow[t]{2}{*}{1} & \multirow[t]{2}{*}{0.1} & \multirow{2}{*}{ area } \\
\hline $\mathrm{p}=0.01$ & $\mathrm{p}=0.05$ & & & & & & \\
\hline $73.3 \mathrm{a}$ & $73.3 b$ & 151.17 & 107 & 66 & 31 & 11 & Key \\
\hline $83.6 \mathrm{a}$ & $83.6 \mathrm{a}$ & 179 & 105 & 74 & 40 & 20 & Reference \\
\hline $36.8 b$ & $36.8 \mathrm{c}$ & 77 & 50 & 35 & 17 & 5 & Critical \\
\hline-- & -- & 135.72 & 87.33 & 58.33 & 29.33 & 12 & Mean \\
\hline
\end{tabular}

The similar letter refer to treatment with non significant difference

Note: Any alphabet of a, b and c refers to a separated statistically group; refer to significant difference between the mean of species number in different areas and plot sizes

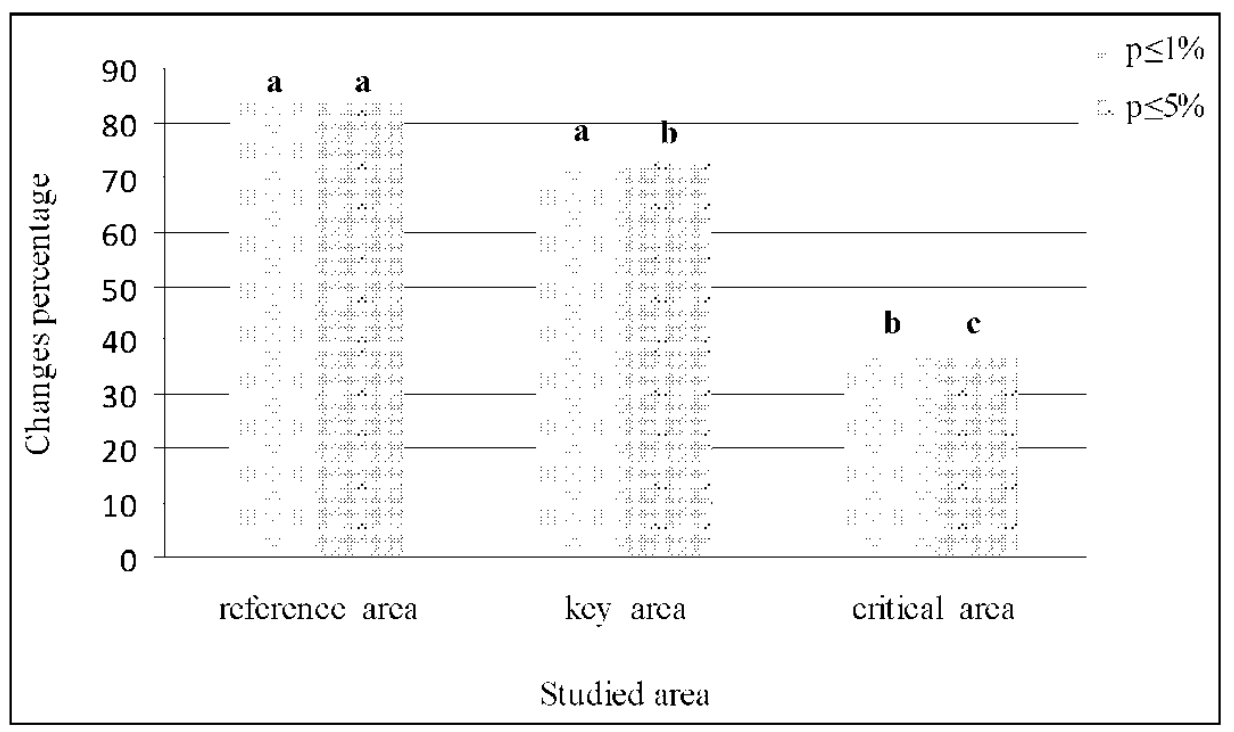

Figure 1. The change of species richness in reference, key and critical area 